\title{
ARTICLE
}

\section{The Normative Nature of the Ecosystem Approach: A Mediterranean Case Study}

\author{
Guillaume Futhazar*
}

First published online 10 November 2020

\begin{abstract}
The purpose of this article is to explore the normative nature of the Ecosystem Approach in international environmental law. To do so, the article examines the implementation of this approach in two Mediterranean regimes: the Barcelona Convention and the General Fisheries Commission for the Mediterranean. As these two regimes have implemented the Ecosystem Approach by taking into account the experiences of other international regimes, they are representative of broader trends in relation to this concept. The examination reveals that the Ecosystem Approach operates as an interstitial principle: a norm that fulfils the functions of a principle with regard to other rules, but is devoid of normative autonomy. This understanding of the Ecosystem Approach brings clarity to a concept that is ambiguous yet is widely disseminated in environmental governance. It may also further the progressive emergence of the Ecosystem Approach as a general principle of international environmental law.
\end{abstract}

Keywords: Ecosystem Approach, Principles and rules, Mediterranean Basin, Barcelona Convention, General Fisheries Commission for the Mediterranean

\section{INTRODUCTION: THE CHALLENGE OF ECOSYSTEMS IN ENVIRONMENTAL GOVERNANCE}

In 1949, American conservationist Aldo Leopold invited us to 'think like a mountain'. To make his point he provided the example of hunters relentlessly killing wolves in fear that they would prey on deer, thus depriving the hunters of their game. In doing so, hunters create an imbalance in the natural system of the mountain. Without any predators,

* Max Planck Institute for Comparative Public Law and International Law, Heidelberg (Germany). Email: futhazar@mpil.de.

I would like to express my sincere gratitude to the people who helped me with this article in its earlier stages. Particularly, the insights of Anne Peters' research group at the Max Planck Institute in Heidelberg (Germany) were crucial in refining my argument.

1 A. Leopold, A Sand County Almanac: And Sketches Here and There (Oxford University Press, 1949), pp. 129-33. 
the deer population explodes as the occasional human hunt is insufficient to maintain them at their usual numbers. This then leads to overgrazing which, in turn, weakens the structural integrity of the mountain soil. With a deteriorated soil the ecosystem of the mountain potentially faces collapse. Without realizing it, hunters threaten the whole mountain environment by killing wolves. This story is just one among many about the unforeseen consequences that human actions can have on the environment if one fails to 'think like a mountain': to understand and to take into account the intricate interrelation that each element in nature may have.

For the last three decades ${ }^{2}$ international environmental law has been trying to think like a mountain. The adoption of the Convention on Biological Diversity $(\mathrm{CBD})^{3}$ in 1992 was a significant step in this direction. This was one of the first global instruments to focus on biodiversity and ecosystems as a whole rather than on specific sectors or issues. Furthermore, the CBD was the first enactment to provide a legal definition of the concept of ecosystems, an important step in the history of this scientific notion. ${ }^{4}$ Article 2 of the CBD defines ecosystems as 'a dynamic complex of plant, animal and micro-organism communities and their non-living environment interacting as a functional unit'. This implies that an ecosystem is greater than the sum of the living and nonliving elements of which it is constituted. It also comprises the different links between these elements, such as nutrient cycles or energy flow; hence, the notion of 'system', where both the elements and their connections make up the whole.

This definition already reveals some of the legal challenges that ecosystems pose for environmental conservation. The effective protection of ecosystems requires the identification of each element within the ecosystem and a precise understanding of how these elements interrelate. ${ }^{5}$ Moreover, the advancement of scientific research on the dynamics of ecosystems has not made things simpler. We now realize that ecosystems are both complex and dynamic. They can change in unforeseen ways and never truly reach a state of equilibrium. ${ }^{6}$ They are constantly evolving. Inflexible laws that conceive of ecosystems as static are therefore contrary to the very nature of the ecosystem. They cannot be managed through fixed and sectoral rules. In this sense they present a

2 Although it can be argued that this trend emerged earlier with treaties, such as the 1971 Ramsar Convention on Wetlands or the 1980 Convention for the Conservation of Antarctic Marine Living Resources. See the Convention on Wetlands of International Importance Especially as Waterfowl Habitat (Ramsar Convention), Ramsar (Iran), 2 Feb. 1971, in force 21 Dec. 1975, available at: https:/www.ramsar.org; and the Convention on the Conservation of Antarctic Marine Living Resources (CCAMLR), Canberra (Australia), 20 Apr. 1980, in force 7 Apr. 1982, available at: https:/www.ccamlr.org/en/organisation/camlr-convention-text.

3 Rio de Janeiro (Brazil), 5 June 1992, in force 29 Dec. 1993, available at: https://www.cbd.int.

4 On the history of the notion of ecosystems, see F. Golley, A History of the Ecosystem Concept in Ecology: More than the Sum of Its Parts (Yale University Press, 1993), and D. Tarlock, 'Ecosystems', in D. Bodansky, J. Brunnée \& E. Hey (eds), The Oxford Handbook of International Environmental Law (Oxford University Press, 2007), pp. 574-96.

5 This can be difficult as we now start to understand the role that microscopic organisms play in ecosystems, e.g., the role of the virus for marine ecosystems is a growing field of research. See, e.g., E.I. de Garcia de Jesus, 'Hundreds of Thousands of Marine Viruses Discovered in World's Oceans', Nature News, 25 Apr. 2019, available at: https:/www.nature.com/articles/d41586-019-01329-w.

6 F.S. Chapin III, P.A. Matson \& H.A Mooney, Principles of Terrestrial Ecosystem Ecology (Springer, 2002), p. 6. 
challenge for the concept of legal certainty according to which legal rules should be clear, predictable, and accessible. ${ }^{7}$

Today, rather than trying to keep ecosystems in a specific state, the goal of conservation and sustainable use is to preserve their integrity. ${ }^{8}$ Integrity is often understood as the ability of ecosystems to maintain their organization or to provide 'ecosystem services'. 9 To achieve this, scientists have argued that a shift is needed in the way in which we protect and manage ecosystems, away from sectoral and piecemeal measures. The preservation of ecosystem integrity can be achieved only through an Ecosystem Approach (EcAp). ${ }^{10}$ As it was incorporated in environmental regimes, the EcAp has become known by many different names and definitions, which makes its exact meaning and purpose unstable. ${ }^{11}$ In the context of this article, I suggest that the EcAp requires that the governance of ecosystems mirrors their interconnected and dynamic nature.

Although the EcAp is becoming a staple element in many environmental regimes, ${ }^{12}$ it has attracted relatively little scholarly attention in comparison with other wellestablished concepts of international environmental law. ${ }^{13}$ Nevertheless, the available scholarship in this area has provided a comprehensive understanding of the history of the EcAp, ${ }^{14}$ its underlying rationales, ${ }^{15}$ and the ways in which various environmental

7 This understanding of legal certainty is based on the reading of the French Conseil d'État, which published, in 2006, a study of the concept. In this report the Conseil d'État analyzed the components of legal certainty and the measures required to achieve it: Conseil d'État, Sécurité juridique et complexité du droit (La Documentation Française, 2006), p. 281. Legal certainty is evidently a broad notion which can be described in numerous other ways, as recalled in M. Fenwick, M. Siems \& S. Wrbka (eds), The Shifting Meaning of Legal Certainty in Comparative and Transnational Law (Hart, 2017). In any case, it should be stressed that reconciling ecosystem governance and legal certainty is not insuperable, as many studies have shown. On this specific issue see F.M. Platjouw \& N. Soininen, 'Reconciling the Rule of Law with Adaptive Regulation of Marine Ecosystems: Challenges and Opportunities for the Arctic and Beyond' (2019) 110 Marine Policy, article no. 103726, pp. 1-3, available at: https:/doi.org/ 10.1016/j.marpol.2019.103726. Vol. 110 of Marine Policy (Dec. 2019) deals mainly with this topic.

$8 \quad$ Tarlock, n. 4 above, p. 577.

9 Ecosystem services are the direct and indirect contributions of ecosystems to human wellbeing. On this topic, see, e.g., The Economics of Ecosystems and Biodiversity (TEEB), Mainstreaming the Economics of Nature: A Synthesis of the Approach, Conclusions and Recommendations of TEEB (Progress Press, 2010).

10 R.E. Grumbine, 'What is Ecosystem Management?' (1994) 8(1) Conservation Biology, pp. 27-38. The notion of ecosystem management is one of the many possible ways of talking about an EcAp. This semantic versatility is highlighted in V. De Lucia, 'Competing Narratives and Complex Genealogies: The Ecosystem Approach in International Environmental law' (2015) 27(1) Journal of Environmental Law, pp. 91-117, at 100-2.

11 De Lucia, ibid.

12 The EcAp was already widely deployed in 2003: see K. Hartje, A. Klaphake \& R. Schliep, The International Debate on the Ecosystem Approach: Critical Review, International Actors, Obstacles and Challenges (Federal Agency for Nature and Conservation, 2003).

13 This is not to say that doctrine on the topic is difficult to find - far from it. For recent and comprehensive contributions on the topic, see V. De Lucia, The Ecosystem Approach in International Environmental Law: Genealogy and Biopolitics (Routledge, 2019); D. Langlet \& R. Rayfuse (eds), The Ecosystem Approach in Ocean Planning and Governance Perspectives from Europe and Beyond (Brill, 2018); F.M. Platjouw, Environmental Law and the Ecosystem Approach: Maintaining Ecological Integrity through Consistency in Law (Routledge, 2016).

14 Platjouw, ibid.

15 De Lucia, n. 13 above; De Lucia, n. 10 above. 
regimes have implemented it. ${ }^{16}$ However, one aspect of the EcAp has yet to be discussed: namely, its normative nature. What is the EcAp in the normative toolbox of international environmental law? ${ }^{17}$

The purpose of this article is to answer this question by studying the implementation of the EcAp in the Mediterranean region. The main argument is that in international environmental law the EcAp can be understood as an interstitial principle: ${ }^{18}$ a norm that fulfils the function of a principle while lacking normative autonomy.

This conclusion will be reached by the following steps. Section 2 will provide the framework for the ensuing inquiry: namely, a working definition of the EcAp and a justification as to why the Mediterranean region is an appropriate case study for determining its overall normative character. The three following sections will then unfold in a syllogistic manner to demonstrate that the EcAp can be understood as an interstitial principle. Section 3 will provide a definition of interstitial principles; Section 4 will examine the implementation of the EcAp in the Mediterranean region; and Section 5 will highlight how this implementation accords with the definition of interstitial principles. Section 6 will then discuss the utility of this inquiry in light of current developments in global environmental governance. The conclusion will summarize the findings of the article.

\section{STUDYING THE ECOSYSTEM APPROACH IN THE MEDITERRANEAN REGION: A REGIONAL INQUIRY FOR A GLOBAL INSIGHT}

The EcAp has been described using many different names and definitions. ${ }^{19} \mathrm{I}$ argue that among this conceptual fuzziness and semantic instability, a common and minimal thread can be found, which provides a clearer understanding of what the EcAp entails: the EcAp requires the governance of ecosystems to mirror their interconnected and dynamic nature. Since its adoption in global fora the EcAp has been incorporated into various environmental regimes. In recent years, it has become a driver for the evolution of the Barcelona Convention ${ }^{20}$ and the General Fisheries Commission for the Mediterranean (GFCM). ${ }^{21}$ These regimes have adopted and implemented the

16 See generally, e.g., Langlet \& Rayfuse, n. 13 above.

17 The term 'normative toolbox' refers to the various techniques that lawmakers in international environmental law can use in order to achieve conservation and sustainable use: e.g., the prevention principle and the precautionary principle are part of this toolbox.

18 The term 'interstitial norm' was coined by Vaughan Lowe in two studies of sustainable development. See V. Lowe, 'Sustainable Development and Unsustainable Arguments', in A. Boyle \& D. Freestone (eds), International Law and Sustainable Development: Past Achievements and Future Challenges (Oxford University Press, 1999), pp. 19-37; and V. Lowe, 'The Politics of Law-making: Are the Methods and Character of Norm Creation Changing?', in M. Byers (ed.), The Role of Law in International Politics: Essays in International Relations and International Law (Oxford University Press, 2000), pp. 207-26.

19 De Lucia, n. 10 above.

20 Convention for the Protection of the Marine Environment and the Coastal Region of the Mediterranean, Barcelona (Spain), 16 Feb. 1976, in force 12 Feb. 1978, available at: https://wedocs.unep.org/handle/20. 500.11822/31970.

21 Available at: http://www.fao.org/gfcm/en. 
EcAp by referring to the experiences of other regional and global regimes. Therefore, what can be learned by studying them is likely to be relevant in other contexts.

\subsection{Restating the Ecosystem Approach}

The history of the EcAp in international environmental law has been studied thoroughly. ${ }^{22}$ The notion made its first explicit appearance in the international law arena in the $1980 \mathrm{~s}^{23}$ and became a widespread element of global environmental governance following its consecration by the Conference of the Parties (COP) to the CBD in 2000. Decision V.6 of COP-5 defines the EcAp as 'a strategy for the integrated management of land, water and living resources that promotes conservation and sustainable use in an equitable way'. ${ }^{24}$ This definition is somewhat vague, and alternative definitions provided in other regimes do not clarify significantly what the EcAp means or requires. The Commission to the Convention for the Protection of the Marine Environment of the North-East Atlantic (OSPAR Commission) ${ }^{25}$ describes the EcAp as:

the comprehensive integrated management of human activities based on the best available scientific knowledge about the ecosystem and its dynamics, in order to identify and take action on influences which are critical to the health of marine ecosystems, thereby achieving sustainable use of ecosystem goods and services and maintenance of ecosystem integrity. ${ }^{26}$

For the Food and Agriculture Organization (FAO), the EcAp for fisheries 'strives to balance diverse societal objectives, by taking into account the knowledge and uncertainties about biotic, abiotic, and human components of ecosystems and their interactions and applying an integrated approach to fisheries within ecologically meaningful boundaries'. In the European Union (EU) context and with regard to fisheries, the EcAp is referred to as ecosystem-based management and defined as:

an integrated approach to managing fisheries within ecologically meaningful boundaries which seeks to manage the use of natural resources, taking account of fishing and other human activities, while preserving both the biological wealth and the biological processes necessary to safeguard the composition, structure and functioning of the habitats of the

22 See Platjouw, n. 13 above; and De Lucia, n. 13 above.

See A. Fabra \& V. Gascon, 'The Convention on the Conservation of Arctic Marine Living Resources (CCAMLR) and the Ecosystem Approach' (2008) 23(3) International Journal of Marine and Coastal Law, pp. 26-37; and H. Wang, 'Ecosystem Management and Its Application to Large Marine Ecosystems: Science, Law and Politics' (2004) 35(1) Ocean Development and International Law, pp. 41-74.

CBD Secretariat, Decision V.6, 'Ecosystem Approach', 15-26 May 2000, para. A.1., available at: https://www.cbd.int/decision/cop/?id=7148.

25 This institution is responsible for overseeing the implementation of the Convention for the Protection of the Marine Environment of the North-East Atlantic (OSPAR Convention), Paris (France), 22 Sept. 1992, in force 25 Mar. 1998, available at: https://www.ospar.org/convention/text.

26 OSPAR Commission, 'Ecosystem Approach', available at: https://www.ospar.org/about/principles/ecosystem-approach. This definition is part of the institutional communication of the OSPAR communication, and was first used in the Joint Ministerial Meeting of the Helsinki and Ospar Commissions in 2003, Bremen (Germany). 
ecosystem affected, by taking into account the knowledge and uncertainties regarding biotic, abiotic and human components of ecosystems. ${ }^{27}$

The list of further definitions is extensive ${ }^{28}$ and the lack of clarity regarding the EcAp has been identified as an obstacle for its appropriation by stakeholders. ${ }^{29}$ Based on the official documents and available literature on the topic, I suggest that the EcAp can be broadly understood as requiring that the governance of ecosystems mirrors their interconnected and dynamic nature. This understanding of the EcAp entails the following prerequisites for environmental governance: (i) physical coherence; (ii) institutional coherence; and (iii) adaptability. Each of these characteristics requires further explanation.

Physical coherence requires the governance of ecosystems to be conducted, as far as possible, by considering the entirety of the targeted ecosystem: its components, the interrelationships between these components, and its links with other ecosystems. The requirement of physical coherence excludes the management of certain parts of an ecosystem in isolation, without taking into account their place and relations with other components of the same ecosystem. However, this condition should not be construed as a requirement of exhaustive knowledge regarding the ecosystem. ${ }^{30}$ Ecosystems are complex and it might prove impossible to achieve an absolute understanding of their composition and dynamic. Such a requirement would render the EcAp impossible to implement in practice. A residual degree of uncertainty is therefore inevitable when implementing the EcAp, ${ }^{31}$ and this uncertainty necessitates political choices to be made on the appropriate course of action. ${ }^{32}$ The EcAp is therefore not a purely scientific and objective way of managing ecosystems, and should not be regarded as such.

Institutional coherence requires that the various instruments and institutions involved with ecosystems should be internally coherent. ${ }^{33}$ Institutional coherence

27 Regulation (EU) No. 1380/2013 on the Common Fisheries Policy, amending Council Regulations (EC) No. 1954/2003 and (EC) No. 1224/2009 and repealing Council Regulations (EC) No. 2371/2002 and (EC) No. 639/2004 and Council Decision 2004/585/EC [2013] OJ L354/22 (Common Fisheries Policy).

28 For an overview of other definitions in marine governance, see R. Long, 'Legal Aspects of Ecosystem-Based Marine Management in Europe' (2012) 26(1) Ocean Yearbook, pp. 417-84, at 420-6.

29 Hartje, Klaphake \& Schliep, n. 12 above, pp. 42-3.

30 See C.L.J. Frid, O.A.L. Paramor \& C.L. Scott, 'Ecosystem-Based Management of Fisheries: Is Science Limiting?' (2006) 63(9) ICES Journal of Marine Science, pp. 1567-72, and S.A. Murawski, 'Ten Myths Concerning Ecosystem Approach to Marine Resource Management' (2007) 31(6) Marine Policy, pp. 681-90, at 684 .

31 As such, the ecosystem approach has conceptual ties with the precautionary approach, as described in A. Trouwborst, 'The Precautionary Principle and the Ecosystem Approach in International Law: Differences, Similarities and Linkages' (2009) 18(1) Review of European Community \& International Environmental Law, pp. 26-37.

32 These political choices may nevertheless be hidden behind a veil of technicality; on this aspect see, e.g., T. Markus, 'Changing the Base: Legal Implications of Scientific Criteria and Methodological Status on What Constitutes Good Marine Environmental Status' (2013) 2(1) Transnational Environmental Law, pp. 145-65.

33 This idea finds support in F.M. Platjouw, 'The Need to Recognize a Coherent Legal System as an Important Element of the Ecosystem Approach', in C. Voigt (ed.), The Rule of Law for Nature (Cambridge University Press, 2013), pp. 158-74. 
echoes physical coherence in that it requires the governance of ecosystems also to have a systemic nature. Therefore, its rules and institutions should relate to each other in a coherent way rather than exist in isolation. Indeed, if an ecosystem is governed by different and internally incoherent rules and institutions, they are likely to clash and their respective goals could be negated. ${ }^{34}$

Finally, the EcAp calls for adaptability in the sense that the governance framework of an ecosystem should allow for change based on the evolution of the ecosystem or the acquisition of new relevant knowledge. ${ }^{35}$ The prerequisite of adaptability is related closely to the notion of physical coherence. Indeed, for physical coherence to be consistently achieved, the EcAp has to be modified to incorporate emerging knowledge about the target ecosystem.

These three elements - physical coherence, institutional coherence, and adaptability are implied in the multiple current definitions of the EcAp. The OSPAR definition, for example, focuses on scientific knowledge to promote adaptability while the CBD definition stresses institutional coherence through the idea of integrated management. The FAO definition indirectly acknowledges physical coherence by referring to ecosystems and their components.

Obviously, this tentative definition is minimalist. The implementation of the EcAp can vary considerably across environmental regimes, where different goals, actors, and political values have a significant influence on its design and implementation. ${ }^{36}$ For example, both the FAO and the CBD consider that humans are beneficiaries and users of healthy ecosystems. As such, both regimes relate the EcAp to participatory decision-making processes and acknowledge the importance of the socio-cultural dimension of ecosystems management. ${ }^{37}$ The EcAp reflects how ecosystems are perceived within a regime, ${ }^{38}$ and what the purpose of their management is. ${ }^{39}$ Yet, despite this variation, EcAps have a common denominator in the idea that the governance of ecosystems should mirror their interconnected and dynamic nature.

As a final caveat, it is important to stress that the proposed definition of the EcAp is valid only within the context of law and environmental governance. As a scientific method, the EcAp is a different notion which, although grounded in a similar

34 E.g., different regimes concerning the same ecosystem might have a different understanding of its boundaries. See A. Westholm, 'Delimiting Marine Areas: Ecosystem Approach(es?) in EU Marine Management', in Langlet \& Rayfuse, n. 13 above, pp. 117-39, at 134.

35 These three requirements are akin to the description of transformative environmental governance proposed by the Intergovernmental Platform on Biodiversity and Ecosystem Services (IPBES) in its latest report. See E.S. Brondizio et al. (eds), Global Assessment Report on Biodiversity and Ecosystem Services of the Intergovernmental Science-Policy Platform on Biodiversity and Ecosystem Services (IPBES Secretariat, 2019), Ch. 6.

36 On the various visions of nature that can be carried by the EcAp, see De Lucia, n. 10 above, pp. 102-3.

37 See CBD Secretariat, Decision V.6, 'Ecosystem Approach', n. 24 above.

38 E.g., humans can be considered as part of an ecosystem, or as managers and beneficiaries who exist outside it.

39 The conservation of an ecosystem can be pursued for the ecosystem's intrinsic value or for the benefit of humans. 
understanding of ecosystems, serves a different purpose. ${ }^{40}$ In particular, the term does not have the same normative connotations as the EcAp in the context of environmental governance.

\subsection{The Barcelona Convention and the GFCM as Representative Examples for the Study of the Ecosystem Approach}

The Mediterranean region holds within itself most of the contemporary issues and dilemmas debated in the field of international environmental law. Identified as a 'hot spot for biodiversity', ${ }^{41}$ the Mediterranean environment is under constant anthropogenic pressure. This pressure has numerous causes, from coastal urbanization, intense marine traffic, land-based pollution and overfishing to climate change and invasive alien species. ${ }^{42}$ Also, despite the strong involvement of scientific communities in research, the Mediterranean environment remains unevenly studied, with many questions left unanswered regarding its current status and its reaction to these anthropogenic pressures. ${ }^{43}$

States for some time have sought to cooperate in order to mitigate human impact on the Mediterranean environment. The region's marine environment is the subject of several international legal agreements pertaining to its conservation and sustainable use. ${ }^{44}$ There is now a dense network of international rules addressed to states with various technical and financial capacities that are illustrative of an obvious north/south divide.

The uniqueness of the environment, anthropogenic pressure, scientific uncertainty, legal density, and a north/south divide are all familiar challenges for international environmental law at the global scale. Each of these is present at the Mediterranean level, making it a laboratory for international environmental governance.

This article focuses on two regimes that implement the EcAp in the Mediterranean region: the Barcelona Convention and the General Fisheries Commission for the Mediterranean (GFCM). The purpose of these regimes differs. While the Barcelona Convention focuses on conservation, the GFCM deals with the exploitation of natural resources. Studying the EcAp in these two contexts enables the identification of common trends despite the divergence in their goals. Moreover, each regime has adopted and implemented the EcAp in an interactive way by taking into account the practices and approaches followed in other regimes, at both global and regional levels. As such, the two regimes are representative of general trends in implementing the EcAp.

40 On this methodological dimension of the EcAp see, e.g., T.D. Scholwater, Insect Ecology: An Ecosystem Approach, $4^{\text {th }}$ edn (Academic Press, 2016), p. 13.

41 A. Cuttelod et al., 'The Mediterranean: A Biodiversity Hotspot under Threat', in J.C. Vié et al. (eds), The 2008 Review of the IUCN Red List of Threatened Species (International Union for Conservation of Nature (IUCN), 2008), pp. 1-13.

42 United Nations Environment Programme (UNEP) \& Mediterranean Action Plan (MAP), State of the Mediterranean Marine and Coastal Environment (UNEP/MAP - Barcelona Convention, 2012).

43 Ibid., p. 85.

44 In a study by the MAP, 16 multilateral environmental agreements were listed as being of particular importance for the region's marine environment: Z. Vernin, Multilateral Environmental Agreements (MEAs) and Guidelines for Southern and Eastern Mediterranean Countries (Plan Bleu, 2016). 


\section{The General Fisheries Commission for the Mediterranean (GFCM)}

The GFCM is the first instance of multilateral international cooperation for the management of natural resources in the Mediterranean. In 1949, under the auspices of the FAO, several Mediterranean states adopted an agreement for the establishment of a general fisheries council to promote the development of fisheries in the Mediterranean region through international cooperation. ${ }^{45}$ This agreement came into force in 1952. However, the Council had only consultative power and did not exert significant influence in the region. It was only in 1997, when the Council became a Commission with an autonomous budget, that it started to have a measurable impact on fisheries in the Mediterranean. ${ }^{46}$ In 2014, the parties to the GFCM adopted the most recent amendment to the constitutive agreement. ${ }^{47}$

On a yearly basis the Commission issues binding recommendations and resolutions addressed to its members to reach its objective of promoting and developing fisheries in the region. These decisions are facilitated by various expert bodies of the Commission which follow the programme of work adopted by the member states.

\section{The Barcelona Convention}

The Barcelona Convention is the child of the Mediterranean Action Plan (MAP). Initiated by the Mediterranean states and the (then) European Community in 1975, the MAP is the first regional sea programme of the United Nations Environment Programme (UNEP). Its original purpose was to assist Mediterranean governments in preventing and controlling pollution in the marine environment. To this end, the MAP was entrusted to draft an international agreement, which was subsequently adopted in Barcelona (Spain) in 1976. The Barcelona Convention for the Protection of the Mediterranean Sea against Pollution was a framework convention which has been complemented by several protocols since its adoption. ${ }^{48}$ It saw its scope extended in 1995 to include the coastal environment. ${ }^{49}$ It was then renamed the Convention for the Protection of the Marine Environment and the Coastal Region of the Mediterranean. ${ }^{50}$

45 Agreement for the Establishment of a General Fisheries Council for the Mediterranean, Rome (Italy), 24 Sept. 1949, in force 20 Feb. 1952, available at: https:/treaties.un.org/doc/Publication/UNTS/ Volume\%20126/volume-126-I-1691-English.pdf.

46 E. Penas Lado, The Common Fisheries Policy: The Quest for Sustainability (Wiley Blackwell, 2016), p. 381. For a detailed account of the 1997 reform, see A. Tavares de Pinho, 'La réforme de la Commission Générale des Pêches pour la Méditerranée' (1997) 2(1) Annuaire de Droit de la Mer, pp. 65-91.

47 Agreement for the Establishment of the General Fisheries Commission for the Mediterranean as amended by the General Fisheries Council for the Mediterranean at its First Special Session (May 1963), at its Thirteenth Session (July 1976), at its Twenty-Second Session (Oct. 1997), and by the General Fisheries Commission for the Mediterranean at its Thirty-Eighth Session (May 2014), Rome (Italy), 20 May 2014, in force 20 May 2014, available at: http://www.fao.org/gfcm/about/legal-framework/en.

48 The list of protocols is available on the website of the MAP, available at: http://web.unep.org/unepmap/ who-we-are/legal-framework.

49 Amendments to the Convention for the Protection of the Mediterranean Sea against Pollution, Barcelona (Spain), 10 June 1995, in force 9 July 2004, available at: https:/treaties.un.org/doc/Publication/UNTS/ Volume\%202942/volume-2942-A-16908.pdf.

50 N. 20 above. 
Like most environmental regimes today, the Barcelona Convention has an institutional architecture which allows for regular review and adaptation. The Mediterranean states meet on a biannual basis to adopt decisions regarding the implementation of the Barcelona Convention and its protocols.

\section{Two regimes influenced by the global evolution of international environmental law}

Both the Barcelona Convention and the GFCM have continuously adapted over time to reflect developments in international environmental law. The Barcelona Convention, for example, underwent important legal reform following the Rio Conference of 1992 in order to incorporate the principles that were formulated in the Rio Declaration. ${ }^{51}$ Similarly, the GFCM has regularly taken note of the international policy developments within the FAO regarding fisheries. ${ }^{52}$ Moreover, the EU exerts significant influence on the evolution and implementation of these regimes. This is apparent, for instance, in the numerous decisions of the GFCM that incorporate elements of the EU Common Fisheries Policy, ${ }^{53}$ or in the current implementation of the EcAp within the MAP.

When it comes to the implementation of the EcAp, several documents demonstrate that both the Barcelona Convention and the GFCM have drawn on other experiences at regional and global levels. For instance, parties and stakeholders to the Barcelona Convention have conducted several meetings to which representatives of other regimes were invited to give presentations on the implementation of the EcAp in other contexts. ${ }^{54}$ This interactive approach has heavily influenced the way in which the EcAp has been designed and implemented in the context of the Barcelona Convention. Similarly, the GFCM, for the purpose of its recent reform to incorporate the EcAp into its legal framework, ${ }^{55}$ explicitly requested that the experiences of other environmental regimes be taken into account for the modernization of the institution. ${ }^{56}$

51 Rio Declaration on Environment and Development, adopted by the UN Conference on Environment and Development, Rio de Janeiro (Brazil), 3-14 June 1992, UN Doc. A/CONF.151/26/Rev.1 (Vol. I), Annex I, available at: http://www.un.org/documents/ga/conf151/aconf15126-1annex1.htm. See also T. Scovazzi, 'Regional Cooperation in the Field of the Environment', in T. Scovazzi (ed.), Marine Specially Protected Areas: The General Aspects and the Mediterranean Regional System (Kluwer Law International, 1999), pp. 81-99.

52 E.g., the GFCM incorporated elements of the FAO code of conduct for responsible fisheries in several of its recommendations and decisions. On the importance of this code, see J. Friedrich, 'Legal Challenges of Nonbinding Instruments: The Case of the FAO Code of Conduct for Responsible Fisheries' (2008) 9(11) German Law Journal, pp. 1539-64.

53 N. 27 above; see also Penas Lado, n. 46 above, pp. 170-87.

54 See MAP, 'Draft: Applying the Ecosystem Approach in the Mediterranean' (2006), UN Doc. UNEP(DEPI)/MED WG.303/2; MAP, 'Report of the Government-Designated Expert Meeting on the Application of the Ecosystem Approach by the Mediterranean Action Plan' (2007), UN Doc. UNEP(DEPI)/MED WG.306/4.

55 The Ecosystem Approach is mentioned in Art. 8 of the Agreement Establishing the GFCM (as amended), n. 47 above. See Section 4.

56 GFCM, 'Report of the Thirty-Fifth Session, Appendix P: Terms of the Reference for a Task Force towards a Possible Revision of the GFCM Agreement, of the Rules of Procedure and the Financial Rules' (14 May 2011); GFCM, 'Validation Meeting of the Task Force, Explanatory Notes; Draft Amendments to the Agreement for the Establishment of the General Fisheries Commission for the 
Therefore, studying the EcAp in the Mediterranean context will not necessarily foster a narrowly Mediterranean understanding of the notion. The 'Mediterranean EcAp' provides a synthesis of other global and regional experiences.

\section{DEFINING INTERSTITIAL PRINCIPLES}

Demonstrating that the EcAp can be understood as an interstitial principle requires a clarification of both terms. In this article, 'principles' are to be understood as a specific type of norm; while 'interstitial' refers to the absence of normative autonomy.

\subsection{Principles as a Type of Norm}

Despite having been discussed profusely in legal doctrine, ${ }^{57}$ 'principles' do not have an overall and unanimously agreed definition. Nevertheless, indications can be drawn from the literature.

Legal principles can be approached either as a source of law, or as a type of norm within a legal system. As a source of law, the questions surrounding principles relate mainly to their identification and their use by judges. This is notably the case in international law, where any reference to 'general principles of law recognized by civilized nations' in the Statute of the International Court of Justice (ICJ) is a subject of debate. ${ }^{58}$ As a type of norm, principles raise various interrogations, such as inquiries into their functions, and the relation and difference between principles and other norms, such as rules. This article engages with the normative aspect of principles. As such, its treatment of the EcAp as a principle is not to be taken as an affirmation of the EcAp as a legal principle, or source, of international environmental law. ${ }^{59}$

Ronald Dworkin, in his seminal analysis, proposed a distinction between principles and rules based on how they operate. Rules are norms which require specific solutions for specific facts. ${ }^{60}$ They impose, authorize or prohibit with precision. They are either

Mediterranean and the Black Sea and Connecting Waters (GFCM) and Draft Rules of Procedure: Explanatory Notes' (2013).

57 See, e.g., R. Dworkin, Taking Rights Seriously (Harvard University Press, 1977), pp. 22-8; J. Raz, 'Legal Principles and the Limits of Law' (1972) 81(2) Yale Law Journal, pp. 823-54; H.L.A Hart, The Concept of Law, $2^{\text {nd }}$ edn (Oxford University Press, 1994), pp. 259-63; R. Alexy, 'On the Structure of Legal Principles' (2000) 13(3) Ratio Juris, pp. 294-304. Principles have also been discussed specifically in environmental law: see N. de Sadeleer, Environmental Principles from Political Slogans to Legal Rules (Oxford University Press, 2002); E. Scotford, Environmental Principles and the Evolution of Environmental Law (Hart, 2017). For more recent discussions on principles see H. Avila, Theory of Legal Principles (Springer, 2007), and M. Borowski (ed.), On the Nature of Legal Principles (Steiner, 2010).

58 This controversy and the need for a better understanding of general principles are summed up in a report on general principles by Marcelo Vázquez-Bermúdez, Special Rapporteur: see International Law Commission, 'First Report on General Principles of Law' (5 Apr. 2019), UN Doc. A/CN.4/732. On this topic see also M. Andenas et al. (eds), General Principles and the Coherence of International Law (Martinus Nijhoff, 2019), and M. Dodeska, General Principles of Law Recognized by Civilized Nations (1922-2018) (Martinus Nijhoff, 2019).

59 The link between these two topics will be discussed further in Section 6 of this article.

60 Dworkin, n. 57 above, p. 24. 
complied with or not. In contrast, principles provide orientation to which positive law must conform through rules. As such, they do not work in the same 'all or nothing' fashion. They can be complied with gradually and there is flexibility in the way in which one can comply. ${ }^{61}$ Speed limitations offer an illustration of this distinction. It can be argued that there is a principle which requires drivers not to drive excessively fast. This principle can take the form of a rule which specifically prohibits driving over 50 kilometres per hour in an urban centre.

This framework of analysis for rules and principles was foundational for the doctrinal debates that followed. In this regard, Robert Alexy's analysis is particularly interesting. In a similar way to Dworkin, Alexy sees rules as specific norms that can either be complied with or not. They are 'definitive commands'. In contrast, principles are 'optimization commands': 'norms commanding that something be realized to the highest degree that is actually and legally possible'. ${ }^{62}$ In his reading, principles are not simply orientations for positive law. They compel lawmakers to adopt specific rules to achieve specific goals.

These understandings of principles and rules highlight the fact that principles have a functional role with regard to rules. According to Gilles Martin, three main functions can be identified. ${ }^{63}$ Firstly, principles are norms that can initiate and legitimize rules. ${ }^{64}$ As an example of this function, Martin refers to the participation and information principle which was translated into numerous precise rules on data sharing and access to justice. ${ }^{65}$ Secondly, Martin stresses the role of principles for the broader coherence of rules. ${ }^{66}$ International law is now marked by a striking legal density and pluralism. In a context where rules are so abundant, principles can help to foster their coherence and avoid conflict. Finally, Martin sees principles as tools of interpretation for rules. In this last function, which is closely related to the idea of coherence, principles are used to ascribe a finality to rules when interpreting them. ${ }^{67}$

In summary, principles are 'optimization commands' that will have an impact on the creation, legitimacy, coherence, and interpretation of rules.

\subsection{The Absence of Autonomy of Interstitial Norms}

Principles can be autonomous, in that they have direct normative power (to impose, prohibit or authorize), or interstitial, operating only through other autonomous norms.

61 Ibid., pp. 26-7.

62 Alexy, n. 57 above, p. 295.

63 G.J. Martin, 'Principles and Rules', in L. Krämer \& E. Orlando (eds), Principles of Environmental Law (Edward Elgar, 2018), pp. 13-22.

64 Ibid., p. 19.

65 Ibid.

66 Ibid., p. 20.

67 Ibid., p. 21. 
The term 'interstitial norm' was coined by Vaughan Lowe in two studies on sustainable development. ${ }^{68} \mathrm{He}$ argues that sustainable development cannot be considered as a rule of international law, as it lacks normativity, is too vague, and - at the time - its exact meaning was disputed. ${ }^{69}$ While Lowe denies the status of international rule to sustainable development, he argues nevertheless that it has a 'normative status'. 70 This normative status is based on the fact that sustainable development has the capacity to influence the interpretation of other rules of international law, and fosters their coherence in specific contexts. ${ }^{71}$ The term 'interstitial' is used to illustrate that sustainable development exists between applicable rules in the interstices. In this metaphor, rules constitute the bricks and interstitial norms are the cement that holds them together and give them coherence. This understanding of interstitial norm suggests that the fundamental characteristic of these norms is their absence of autonomy. In the absence of other rules, they do not have normative impact. On their own, they cannot impose, prohibit or authorize.

Various key legal norms can be considered to be of an interstitial nature. For instance, the principle of good faith ${ }^{72}$ fits clearly in this category, as stressed by the ICJ when it stated that good faith 'is not in itself a source of obligation where none would otherwise exist'. ${ }^{73}$ In contrast, the prevention principle in international environmental law is an example of a principle endowed with normative autonomy. It fulfils the functions of legitimizing, interpreting, and bringing coherence to other rules, but it also directly imposes an obligation, albeit of a broad and general nature, on states.

\section{IMPLEMENTING THE ECOSYSTEM APPROACH IN THE MEDITERRANEAN REGION: MANAGEMENT PLANS AND ECOSYSTEMIC RULES}

This section describes the implementation of the EcAp in both the Barcelona Convention and the GFCM. It highlights that the EcAp can be implemented in various ways, through measures ranging from comprehensive management plans to specific ecosystemic rules, which are designed in light of EcAp requirements.

68 Lowe (1999), n. 18 above; and Lowe (2000), n. 18 above.

69 This reading of sustainable development has been criticized convincingly by Virginie Barral in her studies of the notion: V. Barral, Le développement durable en droit international essai sur les incidences juridiques d'une norme évolutive (Bruylant, 2015); see also, V. Barral, 'Sustainable Development in International Law: Nature and Operation of an Evolutive Legal Norm' (2012) 23(2) European Journal of International Law, pp. 377-400.

70 Lowe (1999), n. 18 above, p. 31.

71 Lowe (2000), n. 18 above, p. 216.

72 For a general overview of this foundational notion of international law see R. Kolb, Good Faith in International Law (Hart, 2017).

73 Case concerning Border and Transborder Armed Actions (Nicaragua v. Honduras), Jurisdiction and Admissibility, Judgment, 20 Dec. 1988, ICJ Reports (1988), p. 69, para. 94. 


\subsection{The Ecosystem Approach as a Management Plan in the Context of the Barcelona Convention}

When the parties to the Barcelona Convention adopted Decision IG.17/6 on the implementation of the Ecosystem Approach in $2008^{74}$ they initiated a process that is only now reaching its conclusion. ${ }^{75}$ Indeed, rather than adopting new rules or amendments that would meet the requirements of the EcAp, they followed the example of other regional regimes - the EU and the OSPAR and Helsinki Commissions ${ }^{76}$ - and established an ambitious management plan for the Mediterranean environment.

This management plan has seven specific steps: ${ }^{77}$

(1) definition of an ecological vision for the Mediterranean;

(2) setting of common Mediterranean strategic goals;

(3) identification of important ecosystem properties and assessment of ecological status and pressures;

(4) development of a set of ecological objectives corresponding to the vision and strategic goals;

(5) derivation of operational objectives with indicators and target levels;

(6) revision of existing monitoring programmes for ongoing assessment and regular updating of targets; and

(7) development and review of relevant action plans and programmes.

The 2008 decision completed the first two steps by stating the ecological vision for the Mediterranean and the common Mediterranean Strategic goals. The vision calls for 'a healthy Mediterranean with marine and coastal ecosystems that are productive and biologically diverse for the benefit of present and future generations' ${ }^{78}$ The three goals laid down to achieve this vision involve the protection of ecosystems, ${ }^{79}$ the reduction of pollution, ${ }^{80}$ and the management of maritime and coastal vulnerability. ${ }^{81}$

Steps 3 to 7 of the management plan required a significant institutional reorganization in order to gather the necessary expertise. Various ad hoc groups undertook a

74 Barcelona Convention Secretariat, Decision IG.17/6, 'Implementation of the Ecosystem Approach to the Management of Human Activities that May Affect the Mediterranean Marine and Coastal Environment' (18 Jan. 2008), UN Doc. UNEP(DEPI)/MED IG.17/10, Annex V.

75 The level of completion of this process is described in MAP, 'Update on the Implementation of the Ecosystem Approach Roadmap' (2019), UN Doc. UNEP/MED WG.467/3.

76 These regimes were referred to explicitly as models to follow and their actors participated in the elaboration of the framework for the implementation of the EcAp in the Mediterranean. This interactivity between regimes is a clear illustration of how the Mediterranean EcAp is the result of a synergetic process: see $n .54$ above.

77 Decision IG.17/6, n. 74 above.

78 Ibid.

79 'To protect, allow recovery and, where practicable, restore the structure and function of marine and coastal ecosystems thus also protecting biodiversity, in order to achieve and maintain good ecological status and allow for their sustainable use'.

80 'To reduce pollution in the marine and coastal environment so as to minimize impacts on and risks to human and/or ecosystem health and/or uses of the sea and the coasts'.

81 'To prevent, reduce and manage the vulnerability of the sea and the coasts to risks induced by human activities and natural events'. 
meticulous literature review and initiated negotiations in order to achieve steps 3, 4 and $5 .^{82}$ The institutional structure for the implementation of the EcAp was reorganized in $2012^{83}$ with the establishment of the Ecosystem Approach Coordination Group to supervise the work of several thematic expert groups. ${ }^{84}$ Most groups worked in collaboration with experts and representatives from other Mediterranean regimes to foster coherence. ${ }^{85}$ This institutional change occurred in the same year as the adoption of a dense set of ecological objectives, ${ }^{86}$ operational objectives and indicators.

The ecological objectives and indicators form a pyramidal structure. To ensure that the first ecological objective is met, four operational objectives are stated, ${ }^{87}$ including the objective of maintaining species distribution. Additionally, two indicators are provided to test whether the operational objective has been achieved. One of these indicators is the distributional range of species (see Table 1)

Each of the 11 ecological objectives is supported by a similar pattern of operational objectives and indicators, thus creating a complex set of goals that all theoretically lead to achieving the strategic goals and, ultimately, the vision adopted in 2008.

However, the attainment of such ambitious goals requires a monitoring programme that allows for a harmonized understanding of the current state of the Mediterranean

82 MAP, 'Report of the Second Meeting of Government-Designated Experts on the Application of the Ecosystem Approach' (2008), UN Doc. UNEP(DEPI)/MED WG.326/4; MAP, 'Report: First Meeting of Technical Experts on the Application of the Ecosystem Approach by MAP' (2011), UN Doc. UNEP(DEPI)/MED WG.347; MAP, 'Report: Third Meeting of Government-Designated Experts on the Application of the Ecosystem Approach by MAP' (2011), UN Doc. UNEP(DEPI)/MED WG.360/7.

83 Barcelona Convention Secretariat, Decision IG.20/4, 'Implementing MAP Ecosystem Approach Roadmap: Mediterranean Ecological and Operational Objectives, Indicators and Timetable for Implementing the Ecosystem Approach Roadmap' (10 Feb. 2012), UN Doc. UNEP(DEPI)MED IG 20/8.

84 The correspondence group on good environmental status and targets; the correspondence group on monitoring; and the correspondence group on economic and social analysis. The first two groups were divided into four clusters: pollution and litter; biodiversity and fisheries; integrated coastal zone management; and hydrologic conditions.

85 E.g., in 2013 the correspondence group on Good Environmental Status held a meeting to which experts from the GFCM and the Agreement on the Conservation of Cetaceans of the Black Sea, Mediterranean Sea and Contiguous Atlantic Area (ACCOBAMS) were invited: MAP, 'Report of the Meeting: Correspondence Group on GES and Targets Biodiversity and Fisheries Cluster, Annex I, List of Participants' (2013), UN Doc. UNEP(DEPI)/MEP WG.373/4. ACCOBAMS, 24 Nov. 1996, in force 1 June 2000, available at: https://accobams.org/documents-resolutions/agreement-text.

86 Decision IG.20/4, n. 83 above. (1) Biological diversity is maintained or enhanced. The quality and occurrence of coastal and marine habitats and the distribution and abundance of coastal and marine species are in line with prevailing physiographic, hydrographic, geographic and climatic conditions. (2) Non-indigenous species introduced by human activities are at levels that do not adversely alter the ecosystem. (3) Populations of selected commercially exploited fish and shellfish are within biologically safe limits, exhibiting a population age and size distribution that is indicative of a healthy stock. (4) Alterations to components of marine food webs caused by resource extraction or human-induced environmental changes do not have long-term adverse effects on food web dynamics and related viability. (5) Human-induced eutrophication is prevented, especially adverse effects thereof, such as losses in biodiversity, ecosystem degradation, harmful algal blooms and oxygen deficiency in bottom waters. (6) Sea-floor integrity is maintained, especially in priority benthic habitats. (7) Alteration of hydrographic conditions does not adversely affect coastal and marine ecosystems. (8) The natural dynamics of coastal areas are maintained and coastal ecosystems and landscapes are preserved. (9) Contaminants cause no significant impact on coastal and marine ecosystems and human health. (10) Marine and coastal litter does not adversely affect coastal and marine environments. (11) Noise from human activities causes no significant impact on marine and coastal ecosystems.

87 Decision IG.20/4, n. 83 above, Annex II: Proposed Ecological Objectives. 
Table 1 Structure of Ecological Objectives, Operational Objectives and Indicators

\begin{tabular}{|c|c|c|}
\hline Ecological Objective & Operational Objectives & Indicators \\
\hline \multirow{5}{*}{$\begin{array}{l}\text { Biological diversity is maintained or enhanced. The } \\
\text { quality and occurrence of coastal and marine } \\
\text { habitats and the distribution and abundance of } \\
\text { coastal and marine species are in line with } \\
\text { prevailing physiographic, hydrographic, } \\
\text { geographic and climatic conditions. }\end{array}$} & $\begin{array}{l}\text { 1.2. Population size of selected species is } \\
\text { maintained. }\end{array}$ & 1.2.1. Population abundance \\
\hline & $\begin{array}{l}\text { 1.3. Population condition of selected } \\
\text { species is maintained. }\end{array}$ & 1.3.1. Population demographic characteristics \\
\hline & \multirow[t]{3}{*}{$\begin{array}{l}\text { 1.4. Key coastal and marine habitats are } \\
\text { not being lost. }\end{array}$} & $\begin{array}{l}\text { 1.4.1. Potential/observed distributional range of certain coastal and } \\
\text { marine habitats listed under SPA Protocol }{ }^{\mathrm{a}}\end{array}$ \\
\hline & & $\begin{array}{l}\text { 1.4.2. Distributional pattern of certain coastal and marine habitats listed } \\
\text { under SPA Protocol }{ }^{\mathrm{b}}\end{array}$ \\
\hline & & 1.4.3. Condition of the habitat-defining species and communities \\
\hline
\end{tabular}

Notes

${ }^{\text {a }}$ Protocol concerning Specially Protected Areas and Biological Diversity in the Mediterranean, n. 112 below.

${ }^{\mathrm{b}}$ Ibid. 
environment. Indeed, if different state parties reach diverging conclusions on the distributional range of a species, it becomes difficult to determine if the distribution of this species has been maintained or not. The EcAp management plan thus requires standardization of how the institutions of and parties to the Barcelona Convention collect environmental data. This last aspect is a highly complex enterprise and was the object of numerous meetings between 2012 and 2016, ${ }^{88}$ which led to the adoption of Decision IG.22/7 on 'Integrated Monitoring and Assessment Programme of the Mediterranean Sea and Coast and Related Assessment Criteria' ${ }^{89}$ Finally, in 2017, the member states adopted the 'Mediterranean Quality Status Report', 90 a detailed document that highlights the knowledge gaps and monitoring obstacles that still exist for each of the ecological objectives.

The final step, involving the 'development and review of relevant action plans and programmes', has recently been completed. The parties to the Barcelona Convention adopted several action plans and programmes in December $2019,{ }^{91}$ all of which have been elaborated as a result of the monitoring activities that were ongoing in the context of the first cycle. The focus for the forthcoming years will be on monitoring activities that support the implementation of the EcAp in the region. ${ }^{92}$

The strategy of the Barcelona Convention for implementing the EcAp has strong similarities with management plans frequently used in the private sector. For example, the seven steps for the EcAp are consistent with the Deming Cycle and its 'plan-do-check-act' rationale. ${ }^{93}$ This managerial approach to compliance can also be seen in the context of the Helsinki Convention, ${ }^{94}$ a regime which was explicitly referred to as an example for the implementation of an EcAp. However, such intricate plans can also be an illustration of 'paralysis by analysis'" where a colossal amount of

88 A summary of the stakes of the monitoring programmes can be found in MAP, 'Secretariat's Gap Analysis on Ongoing Monitoring Activities’ (2013), UN Doc. UNEP(DEPI)/MED WG.386/Inf.4.

89 Barcelona Convention Secretariat, Decision IG.22/7, 'Integrated Monitoring and Assessment Programme of the Mediterranean Sea and Coast and Related Assessment Criteria' (12 Feb. 2016), UN Doc. UNEP(DEPI)/MED IG.22/28.

90 Barcelona Convention Secretariat, Decision IG.23/6, '2017 Mediterranean Quality Status Report' (20 Dec. 2017), UN Doc. UNEP(DEPI)/MED IG.23/23.

91 Barcelona Convention Secretariat, Decision IG.24/7, 'Strategies and Action Plans under the Protocol concerning Specially Protected Areas and Biological Diversity in the Mediterranean, including the SAP $\mathrm{BIO}$, the Strategy on Monk Seal, and the Action Plans concerning Marine Turtles, Cartilaginous Fishes and Marine Vegetation; Classification of Benthic Marine Habitat Types for the Mediterranean Region, and Reference List of Marine and Coastal Habitat Types in the Mediterranean' (5 Dec. 2019), UN Doc. UNEP/MED IG.24/22.

92 MAP, 'Report of the 7th Meeting of the Ecosystem Approach Coordination Group' (2019), UN Doc. UNEP/MED WG.467/18, pp. 9-11.

93 For a brief presentation of the Deming Cycle, see C.N. Johnson, 'The Benefits of PDCA' (2002) 35(5) Quality Progress, p. 120.

94 Convention on the Protection of the Marine Environment of the Baltic Sea, Helsinki (Finland), 9 Apr. 1992, in force 17 Jan. 2000, available at: https:/helcom.fi/about-us/convention. On the implementation of the EcAp in the context of the Helsinki Convention, see B. Bohman, 'The Ecosystem Approach as a Basis for Managerial Compliance: An Example from the Regulatory Development in the Baltic Sea Region', in Langlet \& Rayfuse, n. 13 above, pp. 80-116.

95 D. Langlet \& R. Rayfuse, 'Challenges in Implementing the Ecosystem Approach: Lessons Learned', in Langlet \& Rayfuse, n. 13 above, pp. 445-61, at 448. 
preparatory work at the institutional level hides the fact that there might not be any significant legal change or environmental improvement.

\subsection{The Ecosystem Approach as Ecosystemic Rules in the Context of the GFCM}

In 2014, the EcAp was incorporated into the legal framework of the GFCM through an amendment. Article 8 of the recently amended Agreement Establishing the GFCM lists the adoption of management plans based on an EcAp as one of the functions of the Commission. ${ }^{96}$ However, even before this amendment, the EcAp was present within the structure of the GFCM. Notably, the EcAp served as a guiding principle for the expert bodies of the Commission. ${ }^{97}$ As these bodies are responsible for preparing the recommendations and resolutions ${ }^{98}$ of the GFCM, EcAp requirements were logically incorporated into several recommendations adopted before the 2014 amendments. However, most of these decisions were taken following the release of a performance review of the GFCM in 2011, when the Commission's outdated approaches were harshly criticized. ${ }^{99}$

These recommendations deal, inter alia, with the bycatch of sea birds ${ }^{100}$ and sea turtles. ${ }^{101}$ The concern to limit the impact of the activities of fisheries on associated species shows that the GFCM is attempting to address the impact of fisheries not only on target species but also on ecosystems generally. The same observation can be made regarding the recommendation on the size of fishing nets. ${ }^{102}$ By ensuring that nets will not capture non-target species, the GFCM tries to limit adverse impacts on other elements of the ecosystem. These decisions are in line with the EcAp requirement of physical coherence. ${ }^{103}$ The same can be said of the different restricted fisheries areas established by

96 Agreement for the Establishment of the GFCM (as amended), n. 47 above, Art. 8 ('In accordance with its objectives and general principles, the Commission shall exercise the following functions: ... adopt multiannual management plans applied in the totality of the relevant subregions based on an Ecosystem Approach to fisheries to guarantee the maintenance of stocks above levels which can produce maximum sustainable yield, and consistent with actions already taken at the national level').

97 GFCM, 'Report of the Eighth Session of the Scientific Advisory Committee' (2005), paras 82 and 98 ; GFCM, 'Report of the Sixth Session of the Committee on Aquaculture' (2008), para. 41.

98 These two types of decision are binding. Recommendations concern substantial fisheries matters, while resolutions deal with broader strategic topics.

99 GFCM, GFCM:XXXV/2011/Inf.8, 'Performance Review of the General Fisheries Commission for the Mediterranean and the Black Sea' (20 Jan. 2011), p. 38.

100 GFCM, 'Recommendation 35/2011/3 on Reducing Incidental Bycatch of Seabirds in Fisheries in the GFCM Competence Area' (2011).

101 GFCM, 'Recommendation 35/2011/4 on the Incidental Bycatch of Sea Turtles in Fisheries in the GFCM Competence Area' (2011).

102 GFCM, 'Recommendation 37/2013/2 on the Establishment of a Set of Minimum Standards for Bottom-set Gillnet Fisheries for Turbot and Conservation of Cetaceans in the Black Sea' (2013).

103 It is important to highlight that regulations on bycatch preceded the widespread diffusion of the EcAp. The bycatch of cetaceans has been regulated since the beginning of the 1990s. At the time, the motivation for these rules could be described as informed by a 'proto-ecosystem approach'; see, e.g., R. Caddel, 'Bycatch Mitigation and the Protection of Cetaceans: Recent Developments in EC Law' (2005) 8(2-3) Journal of International Wildlife Law and Policy, pp. 241-59. Despite predating the diffusion of the EcAp, bycatch regulations are still a relevant tool in its implementation; see S.M. Garcia et al., The Ecosystem Approach to Fisheries: Issues, Terminology, Principles, Institutional Foundations, Implementation and Outlook (FAO, 2003), passim and p. 36. 
the GFCM. These areas are tools that can be used to preserve ecosystems in their entirety rather than focusing on a species or a specific practice. If the restrictions are effectively upheld, restricted zones can theoretically allow for the reconstitution of ecosystems. $^{104}$

Although these decisions are consistent with the physical requirements of the EcAp, they lack institutional coherence and adaptability. They concern only specific species or limited areas and lack the overarching character of the management plan adopted by the parties to the Barcelona Convention. Since the amendment of its founding treaty in 2014, the GFCM has moved closer to the management rationale that underpins the MAP. In its 2016 resolution, the GFCM established a 'mid-term strategic plan for sustainable fisheries in the Mediterranean and the Black Sea', ${ }^{105}$ this being the first time that the Commission had adopted such an instrument. ${ }^{106}$ The strategy establishes five targets, ${ }^{107}$ one of which specifies that the GFCM will work towards the reduction of the adverse impact of fisheries on ecosystems. To achieve these targets, several programmes on management ${ }^{108}$ and research ${ }^{109}$ are intended to be adopted to increase the efficacy of existing measures. This recent strategy demonstrates that, within the same regime, different and complementary means can be used to implement the EcAp.

\section{THE ECOSYSTEM APPROACH: AN INTERSTITIAL PRINCIPLE}

After having considered how the EcAp has been implemented in the Mediterranean region, it is now possible to examine whether the EcAp fits the definition of interstitial principles. Such principles, we recall, are non-autonomous norms that can initiate and legitimize rules, foster their coherence, and assist with their interpretation. As demonstrated by its implementation in the Mediterranean, the EcAp clearly fulfils the functions of a principle in relation to rules, while also lacking normative autonomy.

\subsection{The Normative Functions of the Ecosystem Approach}

Both the general premise of the EcAp - that the governance of ecosystems should mirror their interconnected and dynamic nature - and the way in which Mediterranean states

104 GFCM, 'Recommendation 33/2009/1 on the Establishment of a Fisheries Restricted Area in the Gulf of Lion to Protect Spawning Aggregations and Deep-Sea Sensitive Habitats' (2009).

105 GFCM, 'Resolution 40/2016/2 for a Mid-Term Strategy (2017-2020) Towards the Sustainability of Mediterranean and Black Sea Fisheries' (2016).

106 GFCM, 'Report of the Fortieth Session, St. Julian's (Malta), 30 May-3 June 2016' (2016), para. 86.

107 Resolution 40/2016/2 (2016), n. 105 above. 1 - Reverse the declining trend of fish stocks through strengthened scientific advice in support of management. 2 - Support livelihoods for coastal communities through sustainable small-scale fisheries. 3 - Curb illegal unreported and unregulated (IUU) fishing through a regional plan of action. 4 - Minimize and mitigate unwanted interactions between fisheries and marine ecosystems and environment. 5 - Enhance capacity building and cooperation.

108 E.g., GFCM, 'Recommendation GFCM/42/2018/3 on a Multiannual Management Plan for Sustainable Trawl Fisheries Targeting Giant Red Shrimp and Blue and Red Shrimp in the Ionian Sea' (2018).

109 E.g., GFCM, 'Recommendation GFCM/42/2018/7 on a Regional Research Programme on Blue Crab in the Mediterranean Sea' (2018). 
and stakeholders have chosen to implement it confirm its function as a tool for the legitimation, coherence, and interpretation of rules.

The coherence function of the EcAp is the most obvious. The EcAp requires institutional and physical coherence for the governance of ecosystems. In the Mediterranean context, institutional coherence is apparent in the collaborative ways in which the EcAp has been designed and implemented in both the GFCM and the MAP. Additionally, the different monitoring and research programmes allow for a better understanding of the Mediterranean environment, thus ensuring physical coherence. Further, by sharing common goals and common benchmarks to measure whether or not the goals have been achieved, the parties harmonize their activities both in terms of methodology and purpose.

The legitimation aspect of the EcAp can be seen in the numerous ecosystemic rules adopted by the members of the GFCM. Rules on bycatch, fishnet size or restricted areas were adopted to meet the broader requirements of the EcAp. In the context of the Barcelona Convention, this function of the EcAp was illustrated during the last COP, where the abundant work of the various expert groups working under the coordination group led to the adoption of decisions that meet the requirements of the EcAp. ${ }^{110}$

The interpretative function of the EcAp is especially relevant in the context of evolutive agreements. In its general formulation the EcAp will lead to the interpretation of rules to promote coherence and adaptability. When incorporated in more detail into different regimes, the interpretative function of the EcAp becomes more specific. For instance, the Barcelona Convention and its protocols include nebulous or undefined concepts. This is a common feature of international environmental law where deliberately ambiguous terms enable consensus building during the negotiations, but also accommodate evolutive interpretation to incorporate new scientific or political developments. ${ }^{111}$

Article 3 of the Protocol on Specially Protected Areas (SPA Protocol) ${ }^{112}$ requires its parties to 'take the necessary measures to ... protect, preserve and manage threatened or endangered species of flora and fauna'. Interpreting what is meant by 'necessary' is not an easy task, as this word is a prime example of a 'notion à contenu variable' (a term with variable content). ${ }^{113}$ The ever-evolving content of the term 'necessary' allows for the adaptability of the legal framework - what is deemed necessary can change over time - but it may at the same time enable states to escape accountability. A state, for instance, could claim it has taken what it deems to be necessary measures, even though they prove ineffective. By incorporating the EcAp into their legal framework, the parties to the Barcelona Convention have

110 Decision IG.24/7, n. 91 above.

111 On the use of vague terms in treaty making see, e.g., A. Kulick, 'From Problem to Opportunity? An Analytical Framework for Vagueness and Ambiguity in International Law' (2016) 59(1) German Yearbook of International Law, pp. 257-88.

112 Protocol concerning Specially Protected Areas and Biological Diversity in the Mediterranean, Barcelona (Spain), 10 June 1995, in force 12 Dec. 1999, available at: https:/www.unenvironment.org/unepmap/ who-we-are/barcelona-convention-and-protocols.

113 See C. Perelman \& R. Vander Elst (eds), Les notions à contenu variable en droit (Bruylant, 1984). 
developed a dense pyramidal structure of objectives and indicators that specify in detail how they intend to achieve an 'ecological vision'. In doing so, they have clarified significantly what is 'necessary' for the purpose of Article 3 of the Protocol. For example, according to both ecological and operational objectives, ${ }^{114}$ necessary measures must lead to the maintenance of species distributions and the conservation of key coastal and marine habitats. The same logic applies to many other obligations contained in the Barcelona Convention and its protocols. Article 10 of the Protocol for Integrated Coastal Zone Management, ${ }^{115}$ for example, requires its parties to take all necessary measures to protect specific coastal ecosystems. This objective is made less ambiguous by the specifications set out in the EcAp.

Moreover, the interpretative influence of these sets of objectives and indicators is made stronger by the fact that they are contained in unanimously adopted COP decisions. Indeed, these decisions are subsequent agreements in the sense of Article 31(3) (a) of the Vienna Convention on the Law of Treaties. ${ }^{116}$ They are therefore to be taken into account when interpreting the content of the Barcelona Convention and its protocols.

The interpretative influence of the EcAp is also present in the context of the GFCM. The management plans adopted by the Commission are expected to follow the EcAp. ${ }^{117}$ As such, all the decisions adopted to achieve the goals articulated in the management plans have to be interpreted in light of EcAp requirements.

In conclusion, the EcAp clearly operates as a principle in relation to other rules. It is a basis for the creation of those rules, as well as their legitimation, coherence, and interpretation. However, the EcAp is not an autonomous norm.

\subsection{The Lack of Normative Autonomy of the Ecosystem Approach}

The EcAp establishes a series of requirements that apply to the adoption and implementation of norms concerning ecosystems. It exists as a meta-norm which could be summarized as follows: norms concerning ecosystems should take into consideration the entirety of the ecosystems and the other norms applicable to them, and be both flexible and based on the best available knowledge.

The EcAp then distinguishes itself from other well-established principles in international environmental law that have normative autonomy - that is, the ability to prescribe a specific material behaviour. For instance, the principle of sustainable

\footnotetext{
114 See Section 4.1.

115 Protocol on Integrated Coastal Zone Management in the Mediterranean, Madrid (Spain), 2 Jan. 2008, in force 24 Mar. 2011, available at: https://www.unenvironment.org/unepmap/who-we-are/barcelonaconvention-and-protocols.

116 Vienna (Austria), 23 May 1969, in force 27 Jan. 1980, available at: https:/treaties.un.org/doc/ Publication/UNTS/Volume\%201155/volume-1155-I-18232-English.pdf. On the influence of subsequent practice and subsequent agreements, see International Law Commission, 'Second Report on Subsequent Agreements and Subsequent Practice in relation to the Interpretation of Treaties' (26 Mar. 2014), UN Doc. A/CN.4/671; and G. Nolte (ed.), Treaties and Subsequent Practice (Oxford University Press, 2013).

117 Agreement for the Establishment of the GFCM (as amended), n. 47 above, Art. 8.
} 
development requires states to adopt a certain type of behaviour in order to achieve sustainable development. ${ }^{118}$ In the same vein, the prevention principle requires due diligence from states in order to avoid environmental harm. ${ }^{119}$ At the purely theoretical level, ${ }^{120}$ for compliance these principles do not automatically necessitate the adoption of other norms, or the reinterpretation of existing norms. Contrastingly, as this contribution has argued, the EcAp exerts its influence only through other rules and therefore lacks normative autonomy. Thus, the observation of the ICJ on the principle of good faith $^{121}$ also holds true for the EcAp, which 'is not in itself a source of obligation where none would otherwise exist'. ${ }^{122}$

This abstract assessment of the principle is verified at a concrete level. For example, in the context of the Barcelona Convention the implementation of the EcAp took the form of an intricate management plan that can now serve as an interpretation framework for the pre-existing obligations of the Barcelona Convention and its protocols. During the negotiation phase that led to the adoption of the EcAp, partner institutions to the MAP even stated that incorporating the EcAp was not meant in itself to create new obligations, but rather a reorganization of the current normative framework. ${ }^{123}$ Therefore, the EcAp would entail no new legal obligations for the Mediterranean states beyond the development of the management plan. ${ }^{124}$

In the context of the GFCM, the EcAp generated new rules which took into account its requirements. It even led to the adoption of a midterm strategy which has a similar rationale to the management plan in place in the Barcelona Convention. However, its incorporation into the Agreement Establishing the GFCM was considered by the legal office of the FAO as not creating new obligations for the members of the Commission. $^{125}$ In other words, it was not considered an autonomous norm even though it did generate new autonomous rules.

In conclusion, it can be said that the EcAp reshapes existing norms and influences the design of new norms without exercising direct normative influence.

118 As argued in Barral (2015), n. 69 above.

119 See, inter alia, J. Brunnée, 'Procedure and Substance in International Environmental Law and the Protection of the Global Commons', in S. Cogolati \& J. Wouters (eds), The Commons and a New Global Governance (Edward Elgar, 2018), pp. 291-321, L.A. Duvic Paoli, The Prevention Principle in International Environmental Law (Cambridge University Press, 2018).

${ }^{120}$ Obviously, to actually comply with such norms requires the adoption of numerous rules. The density of international environmental law today is a telling illustration of that.

121 Case concerning Border and Transborder Armed Actions, n. 73 above, para. 94.

122 Ibid.

123 MAP (2007), UN Doc. UNEP(DEPI)/MED WG.306/4, n. 54 above, para. 19 ('the Ecosystem Approach was not "a new start" but rather a means to integrate what had been accomplished in terms of international/national obligations and commitments and show that what was being undertaken now was coherent and exhaustive').

124 Ibid., para. 32.

125 FAO, 'General Fisheries Commission for the Mediterranean (GFCM): Proposal to Amend the Agreement' (Sept. 2014), CCLM 99/6, para. 16 ('It is considered that the proposed amendments do not affect existing obligations which de facto and in practice have been expanded'). 


\section{TOWARDS A GREATER RECOGNITION OF}

\section{THE ECOSYSTEM APPROACH}

Understanding the EcAp as an interstitial principle will not in itself bring about better environmental protection or compliance; nor does it offer an exhaustive explanation of the drivers of the diffusion of the EcAp in transnational environmental regimes. ${ }^{126}$ However, this exercise in classification is not without potential consequences for the evolution of international environmental law, both as a discipline and as a legal field.

As pointed out by Elizabeth Fisher, environmental law is a field 'in which the agreed frames, legal and otherwise, for how we understand and act in the world are in a constant state of flux and contestation' ${ }^{127}$ She suggests that when studying rapidly evolving environmental regimes, scholars should engage in rigorous description to make the transformation of environmental law apparent and help to make sense of it. ${ }^{128}$ Only then can trends, strengths, and weaknesses be identified. This exercise can in turn fuel broader discussions outside political arenas, where the immediate pressure to find solutions to environmental problems can inhibit new ideas. ${ }^{129}$

In this sense, reframing the EcAp as an interstitial principle is both descriptive and normative. It is descriptive as it hopes to clarify the operation of the EcAp within environmental regimes, and it is normative as it aims to convince other lawyers and scholars to consider, in an updated way, the content of international environmental law. Indeed, if the EcAp works as a principle from a normative standpoint, one could push for its general recognition as a principle from a source standpoint.

It is clear today that the EcAp is not yet considered to be a source of international environmental law. This is apparent in both legal scholarship, where most studies of the principles of environmental law do not mention the EcAp, and in the Mediterranean negotiations that led to its adoption in the GFCM and the Barcelona Convention. Indeed, none of the participants in those negotiations considered that the EcAp could be a new principle of international law. ${ }^{130}$ However, the EcAp as a principle of international environmental law is increasingly gaining traction. For example, the latest draft of an International Legally Binding Agreement on the Conservation and Sustainable Use of Marine Biological Diversity of Areas Beyond National

126 De Lucia, n. 13 above.

127 E. Fisher, 'Environmental Law as "Hot” Law' (2013) 25(3) Journal of Environmental Law, pp. 347-58.

128 Ibid., p. 354.

129 As argued in D.M. Maldonado, 'Environmental Law Scholarship: Systematization, Reform, Explanation and Understanding', in O.W. Pedersen (ed.), Perspectives on Environmental Law Scholarship (Cambridge University Press, 2018), pp. 41-59.

130 When the parties to the Barcelona Convention amended the treaty in 1994, they did so to incorporate the new principles listed in the Rio Declaration of 1992, n. 51 above. When it came to implementing the EcAp, they chose to rely only on COP Decisions. Similarly, during the process of modernization of the GFCM, the EcAp was mentioned together with the precautionary approach in the preamble of one draft for a new agreement establishing the GFCM. The EcAp was removed and only left in Art. 8: Validation Meeting of the Task Force, Split (Croatia), 10-11 May 2013, 'Draft Amendments Agreement for the Establishment of the General Fisheries Commission for the Mediterranean and the Black Sea and Connecting Waters (GFCM)' ('Mindful that effective conservation and management measures must be based on the best scientific information available and on the application of the precautionary approach and an Ecosystem Approach to fisheries management'). 
Jurisdictions ${ }^{131}$ lists the EcAp among its general principles and approaches. ${ }^{132}$ This agreement will be crucial in the future development of the law of the sea, and the EcAp will be a pillar for this instrument.

Acknowledging the status of the EcAp as a principle in its iteration as a source of law, given that it represents an increasingly ubiquitous principle in its alternative meaning as a norm, could strengthen international environmental law as a whole. For instance, the obligation to conduct an environmental impact assessment (EIA) is now recognized as a principle of general international law. ${ }^{133}$ However, the scope and substance of such assessments are not specified under international law. ${ }^{134}$ Should the EcAp be recognized as a legal principle, it would at least influence the EIA obligation. This interplay of norms would imply that EIAs are required to consider ecosystems in their entirety to meet the requirements of the EcAp.

Additionally, pushing for the acknowledgement of the EcAp as a principle of international environmental law would theoretically ensure that any future rules in this field are designed, interpreted, and implemented in a way that complies with the requirements of this interstitial principle. This would help to enhance the substantial design of international environmental law.

\section{CONCLUSION}

The requirement that the governance of ecosystems should mirror their interconnected and dynamic nature, or the EcAp, presents a key challenge for the traditional structures of law. It requires legal systems to embrace complexity and instability, two characteristics that do not sit well with the fundamental notion of legal certainty. However difficult this shift might be, it is nevertheless urgently needed if we hope to maintain our global environment in a state where human life is possible.

Even though the EcAp has become a common element of many environmental regimes, it is not yet considered to be a fundamental principle of international environmental law, in contrast to the prevention principle and sustainable development. The conceptual ambiguity of the EcAp is often cited as a reason for the reluctance of stakeholders to adopt it. ${ }^{135}$ This article has attempted to clarify the notion from a normative perspective by arguing that the EcAp operates as an interstitial principle. Of course, this qualification by itself does not make implementing

131 Intergovernmental Conference on Marine Biodiversity of Areas Beyond National Jurisdiction, 27 Nov. 2019, Revised Draft Text of an Agreement under the United Nations Convention on the Law of the Sea on the Conservation and Sustainable Use of Marine Biological Diversity of Areas Beyond National Jurisdiction.

132 Ibid., Art. 5. In previous versions, the EcAp was not mentioned: UN General Assembly, 'Draft Text of an Agreement under the United Nations Convention on the Law of the Sea on the Conservation and Sustainable Use of Marine Biological Diversity of Areas Beyond National Jurisdiction' (17 May 2019), UN Doc. A/CONF.232/2019/6.

133 Pulp Mills on the River Uruguay (Argentina v. Uruguay), Judgment, 20 Apr. 2010, ICJ Reports (2010), p. 14, para. 204.

134 Ibid., para. 205.

135 Hartje, Klaphake \& Schliep, n. 12 above, pp. 42-3. 
the EcAp any easier. Ecosystems are complex entities, and the gaps in our knowledge remain a challenge for their management. However, understanding the normative character of the EcAp could help to facilitate its broader diffusion and adoption, thus favouring its emergence as a principle of international environmental law in the broadest sense, both as a norm and as a source. 